\title{
Dinámicas de dominación y sumisión en Perra brava de Orfa Alarcón
}

Este artículo analiza la relación de sumisión y dominación consensual entre Fernanda y el narcotraficante Julio en la novela Perra brava (2010) de la autora mexicana Orfa Alarcón. La teoría que fundamenta este ensayo se basa en los estudios de Andrea Beckmann, Staci Newmahr y Margot Weiss sobre el BDSM consensual y en la dialéctica del señor y el esclavo de Friedrich Nietzsche. Se examina cómo la relación entre Fernanda y Julio cambia cuando Julio reconoce que Fernanda posee valores éticos similares a los suyos. Debido a esto, Fernanda se empodera porque deja de ser inferior, aunque Julio sigue siendo superior.

Palabras clave: sumisión, dominación, narcotráfico, empoderamiento femenino

This article analyzes the relationship of submission and dominance between Fernanda and the drug trafficker, Julio, in the novel Perra brava (2010), by Mexican female author Orfa Alarcón. The theory that undergirds the article follows work by Andrea Beckmann, Staci Newmahr, and Margot Weiss on consensual BDSM as well as Friedrich Nietzsche's master-slave dialectic. The article examines how Fernanda and Julio's relationship changes when Julio acknowledges that Fernanda has ethical values similar to his. Although Julio does not stop being "top" in the relationship, as "bottom," Fernanda manages to empower herself.

Keywords: submission, dominance, drug trafficking, female empowerment

En su libro Sadomasochism in Everyday Life: The Dynamics of Power and Powerlessness (1992), Lynn Chancer propone que las sociedades patriarcales, capitalistas, racistas y homofóbicas son en realidad sociedades en las cuales un grupo domina y otro es dominado, por lo que se trata de sociedades que manifiestan condiciones de sadomasoquismo (33-34). Según Chancer, las características sadomasoquistas de estas sociedades no se establecen a través de un acuerdo intencional entre los grupos superiores (dominantes) e inferiores (sumisos). En el caso de las relaciones consensuales del BDSM (bondage [ataduras] / disciplina / dominación /

REVISTA CANADIENSE DE ESTUDIOS HISPÁNICOS 42.2 (PRIMAVERA 2OI8) 
sumisión / sadismo / masoquismo), este acuerdo intencional entre los participantes sí existe. De hecho, en el BDSM consensual, los participantes aceptan voluntariamente reglas específicas, y pueden detener y terminar la relación cuando así lo deseen. Por el contrario, en las sociedades a las que Chancer se refiere, las personas que están en una posición socioeconómica inferior - y que sustentan el funcionamiento de dichas sociedades - nunca tienen el poder porque el grupo superior no se comporta de acuerdo con las necesidades y deseos del grupo inferior.

Las prácticas del BDSM consensual, como señala Margot Weiss, están conectadas a las formaciones culturales capitalistas (6). Debido a esto, pueden reflejar, parodiar o desnaturalizar la cultura capitalista (Weiss 6). Por tanto, entender cuestiones de dominación y sumisión consensuales permite observar cómo se ejerce poder sobre los oprimidos y cómo funcionan las jerarquías. La novela Perra brava (2010) de la escritora mexicana Orfa Alarcón presenta una relación consensual de sumisión y dominación entre la protagonista Fernanda Salas y el narcotraficante Julio Cortés. ${ }^{2}$ Debido a que la crítica literaria no ha examinado este aspecto de la obra, con base en la teoría sobre el BDSM, este ensayo analiza cómo la relación consensual funciona como un espejo que critica el contexto del mundo del narcotráfico. Se propone que, aun cuando Julio es el "superior", él no determina todos los aspectos de la relación, puesto que el poder entre él y Fernanda fluctúa a lo largo de la novela. Cuando Julio la reconoce como igual, es decir, como un "superior" como él, Fernanda se convierte en un "inferior" con poder que puede amenazar el poder de Julio.

Esta obra de Alarcón se ubica dentro de la narcoliteratura en México, género originado en el norte del país. Algunos de los escritores más conocidos en este género literario son Élmer Mendoza, Bernardo Fernández Bef, Alejandro Almazán y Víctor Ronquillo. Como indica Diana Palaversich, la novela de Alarcón es importante dentro de este contexto porque presenta un aspecto menos explorado, el de la perspectiva de la mujer y de una escritora (6o). Aun cuando en Perra brava el narcotráfico funciona como "telón de fondo" y no como temática principal (Palaversich 60), analizar la poco tradicional relación de pareja entre Fernanda y Julio revela dinámicas de género y poder del tráfico de drogas en México.

Guillermo Núñez Noriega y Claudia Esthela Espinoza Cid señalan que el narcotráfico funciona como un "dispositivo de poder sexo-genérico" que reproduce reglas tanto de género como de sexualidad en los individuos (93). Debido a que este mundo perpetúa nociones de masculinidad y heterosexualidad (Núñez y Espinoza I07-08), la relación de dominación y sumisión consensual entre Fernanda y Julio revela estos sistemas patriarcales al tiempo que los critica. Las dinámicas de sumisión y 
dominación tienen el poder de desvelar construcciones sociales porque, como explica Michel Foucault, en la sociedad hegemónica lo que se considera como perversión se encuentra en la periferia de la sexualidad "normal". Según Foucault, la marginalización de ciertos tipos de sexualidades explica cómo las reglas sobre la sexualidad operan por exclusión en la sociedad (62). Todo aquello que el heteropatriarcado no desea, como la sumisión y la dominación consensuales, es rechazado y puesto bajo sospecha.

Antes de comenzar el análisis de la novela, debe aclararse el vocabulario que se utiliza en este artículo. Así por ejemplo, se prefiere el "BDSM" a términos como "sadomasoquismo" y "SM", para evitar una referencia exclusiva al enfoque de explotación socioeconómica y política que adopta Chancer. Aun cuando Staci Newmahr considera que el acrónimo BDSM borra distinciones y reduce la amplia gama de las prácticas, este ensayo opta por dicho acrónimo ya que enfatiza dinámicas de dominación y sumisión (I8). Además, y como explica Weiss, el "BDSM" es el término preferido por la comunidad pansexual (vii). Por último, se usan los términos "inferior" y "superior" para referirse a "bottom" y "top" respectivamente. La definición de estas palabras se basa en la acepción amplia que les da Newmahr, como "categories of play and players that can subsume other scene identities, including dominant, submissive, sadist, and masochist" (I9). En este ensayo, de ninguna manera "superior" e "inferior" remiten a discursos que perpetúan el desbalance de poder.

Perra brava está narrada por Fernanda, su protagonista, y desde la primera frase de la novela, "Supe que con una mano podría matarme" (Alarcón II), ella deja en claro que Julio es el superior en la relación. Debe enfatizarse que se trata de una relación consensual en la que, como sumisa, Fernanda es consciente del peligro que corre, pero aun así continúa su relación. Se podría cuestionar que la sumisión de Fernanda no es consensual, porque ella se involucra con un narco que la podría matar en cualquier momento, pero este ensayo considera que su sumisión es voluntaria, ya que ella así lo explica y porque ama a Julio. El consentimiento de Fernanda posee connotaciones que otras relaciones consensuales del BDSM no tienen, ya que relacionarse con Julio implica involucrarse en el mundo del tráfico de estupefacientes. Al mismo tiempo, el aspecto consensual de la sumisión de Fernanda es el elemento que expone con más fuerza que dicho mundo funciona a partir de la opresión. Como ya se mencionó, las prácticas consensuales del BDSM reflejan y cuestionan la cultura capitalista y, en la novela de Alarcón, la opresión y la violencia del narcotráfico se tornan más evidentes, debido a que contrastan radicalmente con la sumisión voluntaria de la protagonista. La novela refleja el riesgo que 
Fernanda corre y también lo desarrolla como tema con el propósito de mostrar cómo una relación consensual de sumisión y dominación se enlaza con el complejo juego de poderes del narcotráfico, como se analiza más adelante.

Julio se establece en la posición superior no sólo por su poder en el plano socioeconómico, sino también por el que tiene en los planos físico, afectivo y sexual. Respecto a cuestiones socioeconómicas, su dinero le permite a Fernanda conseguir el estatus deseado, como, por ejemplo, tener un carro, aunque sea él quien decide cuál. Su poder socioeconómico como jefe narcotraficante también se revela en cómo ella puede y debe mostrarse en público, ya que siempre la acompaña al menos uno de sus hombres a manera de guardaespaldas. En ciertas ocasiones, él le escoge la ropa y la lleva a fiestas como si fuera objeto de exhibición. Es evidente que Julio trata a Fernanda como un objeto, puesto que determina y dicta su vida en relación con aspectos socioeconómicos y físicos.

Puede verse que ella desempeña el rol de la "mujer trofeo", que es el término con el que José Manuel Valenzuela Arce identifica a las mujeres relacionadas sentimentalmente con traficantes que se destacan por tener una apariencia física atractiva ( $15 \mathrm{I}$ ), que para el caso son los patrones de la belleza europea tradicional. "Buchona" es otro término usado para referirse a este tipo de mujeres quienes, a partir de su apariencia y sexualidad, buscan ventajas económicas de los narcotraficantes (Jiménez Io9). Pero, como se verá, Fernanda no es ni la típica mujer trofeo ni la típica buchona. La relación de sumisión y dominación consensual hace que Fernanda sea diferente de otras buchonas.

La dominación de Julio está presente también en los planos físicos y de la sexualidad, como se establece desde el primer capítulo de la novela: "Él comenzó a morderme los senos y me sujetó ambos brazos, como si yo fuera a resistirme. Nunca me opuse a esta clase de juego. Me excitan las situaciones de poder en las que hay un sometido y un agresor" (Alarcón II). Fernanda establece con Julio un acto sexual consensual en el que obtiene placer cuando es dominada por él, por lo que se destaca que ella siente placer en su sumisión. Los roles de sumisión y dominación en dos momentos posteriores del mismo capítulo adquieren más dimensiones. En el primero, al continuar teniendo sexo con Julio, Fernanda dice que "el dolor le ganaba lugar al placer y yo sólo quería que me dejara respirar, que terminara antes de que me rompiera algún hueso" (I2). A pesar de encontrarse en una relación consensual, ella pasa a sentir más dolor que placer y a temer por la integridad de su cuerpo. Este episodio no sólo muestra abuso y violencia doméstica, sino que también destaca la sumisión de Fernanda, ya que ella explica que "Julio al fin se vino y se quedó dormido. 
Me abracé contra él" (I2). Ella es una sumisa voluntaria en una relación en la cual sólo Julio toma decisiones y su placer sexual es prioritario. Es importante recalcar también que en ningún momento Fernanda considera que se trata de una violación y, de hecho, enfatiza el querer estar cerca de Julio.

La asfixia, miedo, dolor y espera de Fernanda son un referente inmediato al abuso sexual entre parejas, pero el texto más que reproducir ese abuso lo hace evidente a través de la compulsiva dependencia emocional, económica y física de Fernanda, como cuando abraza a Julio. Al tener en cuenta, como señala Weiss, que las dinámicas del BDSM consensual hacen repensar las relaciones o estructuras de la sociedad (25), el placer, la asfixia, dolor, espera y miedo de Fernanda poseen cuatro funciones. Primero, desnaturalizan ideas patriarcales sobre el "placer" de las mujeres, debido a que la ideología tradicional considera que las mujeres no sienten placer durante el acto sexual. Segundo, exponen el rol de sumisión histórico de la mujer en el que el placer sexual del hombre es prioritario, ya que Julio representa al "gran macho", al hombre heterosexual cuya sexualidad agresiva se impone a la de su pareja. Fernanda muestra esa sumisión tradicional al darle prioridad al placer de Julio y olvidarse del propio. Tercero, la condición emocional y física de Fernanda expresa el contexto machista del narcotráfico, ya que el jefe tiene prioridad en todo. De esta manera, la relación entre los dos personajes enfatiza la masculinidad tóxica del tráfico de drogas, es decir, la masculinidad que perpetúa estereotipos sobre la violencia inherente en los hombres. Y cuarto, el placer, la asfixia, el dolor, la espera y el miedo muestran que el inferior en el mundo del narcotráfico no puede oponerse a o contrarrestar el poder del superior. A primera vista parece tratarse de una sociedad sadomasoquista como la describe Chancer, pero la novela justamente problematiza esa jerarquía, porque los roles de Fernanda y Julio se modifican, como se explica después.

Tradicionalmente la sexualidad ha estado organizada en sistemas de poder que recompensan y castigan (Rubin I8o). Para Gayle Rubin, debido a que estos sistemas no reflejan los valores vigentes en las sociedades contemporáneas, tienen que ser analizados y puestos al día, ya que no se debe marginar a personas y comunidades por su gusto o comportamiento erótico (I8I). Por tanto, explicar las dinámicas del deseo de Fernanda y su estatus de inferior no implica justificar la violencia o de la subordinación de las mujeres, sino entender que la sumisión y dominación consensuales son prácticas que ocurren en todas las sociedades. Este ensayo no busca disminuir la importancia y frecuencia de las violaciones entre parejas, sino comprender cómo los roles de Fernanda y Julio reflejan la sociedad en la que viven. 
En las relaciones consensuales del BDSM, el inferior posee una contraseña que debe usar en caso de que no esté de acuerdo con el proceder del superior y quiera interrumpir una práctica en cualquier momento. Debido a esta dinámica, se considera que el inferior detenta el poder en la relación porque es quien establece los límites que el superior debe respetar. En la novela, sin embargo, no hay una contraseña con la que Fernanda pueda interrumpir a Julio, situación que refleja el abuso y muestra la condición de Fernanda como inferior absoluta. Debido a que en ningún momento Fernanda le pide a Julio que se detenga o cambie su actitud, la relación entre ellos expone otra dimensión de la relación. Además de esperar a que él termine el acto sexual, al describir los juegos sexuales que tiene con él, Fernanda lo considera un "agresor" y no "dominante" o "superior" (Alarcón II). Puede verse que la relación se basa en que Fernanda establece a Julio como superior agresivo, no sólo por su poder económico, sino también por la violencia física que ejerce sobre ella. Debe mencionarse que aunque Fernanda nunca obtiene una contraseña con la cual pueda imponerle límites a la dominación de Julio, ella consigue establecer tales límites una vez que él la reconoce como superior, como se comenta más adelante.

$\mathrm{Al}$ analizar el segundo momento del primer capítulo mencionado antes, se observa que la dominación de Julio también reproduce violencia psicológica y, aunque sea sumisa, Fernanda tiene una agenda. Después de haber terminado el acto sexual descrito antes, Fernanda se da cuenta de que él estaba cubierto de sangre y que la había untado de sangre a propósito (Alarcón I2). Debido a que a ella no le gusta ni ver ni oler sangre, Julio había cubierto su propio cuerpo de sangre humana para que cuando lo lamiera se le quitara lo "fresita", lo quisquillosa (I2).3 Él desconoce que Fernanda posee hemofobia o hematofobia (miedo a la sangre), y ve su fobia como una cuestión superficial.4 Al untarse la sangre de un amigo asesinado (I2-I3), es evidente que Julio detenta un poder que reproduce la violencia del mundo del narcotráfico. Aun si Fernanda es estudiante universitaria y vive con Julio, ella no está directamente relacionada con el negocio y su violencia, pero él se lo recuerda tanto física como psicológicamente. Además, maltratar a Fernanda significa que Julio no la considera su igual, sino alguien a quien puede oprimir sin sufrir ninguna consecuencia. Como sumisa, ella representa un lugar seguro para su despliegue de poder, puesto que no lo reta, no lo amenaza y él piensa que ella no lo puede destruir.

La hemofobia también tiene otras connotaciones, debido a que se originó en un episodio de violencia doméstica en la familia de Fernanda. Cuando ella tenía seis años, su padre asesinó a su madre, y ella quedó atrapada debajo del cuerpo de su madre hasta que su hermana la rescató (Alarcón 26). Debido a este crimen, la misma novela establece la idea de que 
Fernanda está con Julio porque él representa y continúa la violencia paterna. Varias veces el padre de Fernanda se había emborrachado y golpeado a su madre hasta dejarla inconsciente (176). Sin embargo, Fernanda aclara que obedecía a Julio porque él la protegería de su padre en caso de que este último volviera (65). Aun si ella es inferior, se hace evidente que ella tiene una agenda: necesita de alguien más violento que su padre (otro tipo de "agresor") para resguardarse. Itzelín R. Mata-Navarro señala que hay que distanciarse de los papeles binarios de victimaria o víctima cuando se analiza la figura de la buchona, para entender las situaciones sociales que hacen que el tráfico sea una opción de vida (I45). Fernanda es más que una simple víctima de Julio, pero tampoco es la victimaria que solamente se aprovecha del poder Julio. Ella no representa el estereotipo de la buchona o mujer trofeo, puesto que su interés en Julio va más allá de bienes materiales y una posición social.

En el texto, la violencia del narcotráfico tiene una función doble, porque por una parte es hipérbole de la violencia intrafamiliar, ya que representa una exageración del maltrato físico y emocional y, por otra parte, protege a las víctimas de violencia doméstica porque tiene los recursos para hacerlo. Puede verse esta relación entre los dos tipos de violencia en la reseña sobre Perra brava de Yanet Aguilar Sosa ya que, al ser entrevistada con respecto a Fernanda, Alarcón dice que: "Para llevar a ese personaje al maltrato máximo la metí a este ambiente de sicarios, de narcos, de violencia y balazos". La relación consensual entre Fernanda y Julio refleja la violencia del narcotráfico y la intrafamiliar, y cómo pueden estar conectadas. La relación entre estos dos personajes, por tanto, expone y problematiza el pasado de Fernanda y graves problemas sociales, no sólo el del narcotráfico sino también el de la violencia doméstica.

Es importante recordar que las dinámicas del BDSM consensual, como indica Andrea Beckmann, están ausentes de representaciones públicas (2). De hecho, la gran mayoría de las representaciones públicas de instancias del BDSM consensual están permeadas por connotaciones exóticas y negativas. En el caso de Latinoamérica, todavía se trata de un tema tabú que se rechaza, oculta o representa con base en estereotipos y que no se acepta como práctica recurrente. De aquí que sea importante analizar la relación entre Fernanda y Julio y mostrar si la novela se aleja de estereotipos sobre el mundo del BDSM. Exponer la conexión entre violencia doméstica y la violencia del narcotráfico cuestiona el estereotipo de que la violencia en México solo la producen los traficantes, al mismo tiempo que presenta el tema del feminicidio.

La superioridad de Julio, además de darse en los planos físico, socioeconómico y sexual, se justifica principalmente en el plano afectivo. 
Fernanda lo ama, y no hay otro hombre sobre la tierra como Julio; ni siquiera hay un hombre tan bello físicamente como él (Alarcón I4). El primer capítulo de la novela posee cinco secciones en números romanos, en las cuales Fernanda explica cómo conoció a Julio, pero cada una se refiere a un lugar y momento diferente como si lo hubiera conocido bajo diversas circunstancias y varias veces. Fernanda explica esta multiplicidad de encuentros al decir que: "A partir de Julio no hubo uno más, no hubo ninguno antes" (22), por lo que se deduce que todas las historias de ella pasaron a girar alrededor de él. Julio domina hasta en las relaciones sentimentales y sexuales anteriores de Fernanda. La novela confirma que Fernanda no es la buchona que está con Julio por beneficios económicos solamente, ya que verdaderamente lo ama. La superioridad de Julio también se basa en el consentimiento, amor, deseos y necesidades de Fernanda.

A pesar de su inmenso amor, Fernanda desvía su atención de Julio por primera vez cuando en una fiesta se besa con Mónica, la jefa narcotraficante de Sinaloa.5 Si la relación entre Julio y Fernanda implica comportamientos que no son normativos dentro de la visión tradicional de la sexualidad, el beso que puede mostrar que Fernanda no es heterosexual, sino no monosexual (bisexual), es excluido de los comportamientos transgresores, debido a que no fue autorizado por Julio y amenaza su acuerdo heterosexual y machista con Fernanda. De hecho, al verla besándose con Mónica, Julio siente un coraje muy grande (Alarcón 99). Después del beso, él golpea a Fernanda y la deja sola en la casa sin dinero y sin carro, pero se disminuye la importancia del beso, porque Fernanda continúa adorando a Julio. El acto no monosexual representa, entonces, la necesidad de atención que ella quería de Julio durante la fiesta, y no se desarrolla como identidad u orientación.

Además de operar como la perversión que muestra la heteronormatividad establecida por Julio, retomando el postulado de Foucault sobre cómo las sexualidades que no son normativas muestran el funcionamiento del heteropatriarcado (62), el beso revela la jerarquía de poderes del narcotráfico y la fragilidad de la posición de Julio, porque él no es el único jefe. Elizabeth Sánchez Garay estipula que Perra brava no ofrece una visión crítica y compleja del narcotráfico (Io9), pero debe considerarse que la novela muestra que una mujer joven y atractiva no siempre es una estereotípica buchona, y que las mujeres pueden detentar el poder en el tráfico de drogas. Aun en el ambiente machista del narcotráfico, una jefa puede amenazar el poder de otro jefe al cuestionar la estabilidad de su vida privada. Es decir, aunque el poder en este mundo tradicionalmente ha estado concentrado en hombres cisgénero que reproducen las normas del heteropatriarcado, la obra confirma que el poder no está necesariamente 
concentrado en un sexo o performance de género específico. Mónica representa a mujeres tales como Ignacia Jasso, Lola la Chata, Sandra Ávila Beltrán, Manuela Cano, Enedina Arellano Félix, entre otras, que en la historia mexicana han sido consideradas importantes jefas traficantes. ${ }^{6}$ Asimismo, al tener en cuenta que muchas de ellas heredaron el poder por la muerte de su esposo o familiar traficante, Fernanda puede llegar a ser mucho más que mujer trofeo y buchona.

Después de haber sido golpeada y abandonada, Fernanda solamente se reconcilia con Julio cuando confirma su sumisión al sacrificarse por él y confirmar el pacto heterosexual entre ellos. Uno de los hombres de Julio lo traiciona porque le devuelve el carro a Fernanda, y deja la cabeza de un ser humano en el asiento de atrás. Cuando la policía descubre la cabeza, Fernanda se inculpa para evitar que Julio vaya a la cárcel (Alarcón 74). Dado que el beso no monosexual hace que Julio castigue a Fernanda, solamente el sacrificio público de sumisión extrema, que consagra la fidelidad hacia él, lo hace perdonarla. El sacrificio también pone en evidencia que Julio rige su afecto, sexualidad y vida privada por cuestiones conectadas a la vida pública.

$\mathrm{Al}$ atribuirse el crimen, el sacrificio de Fernanda se constituye en el mayor nivel de sumisión voluntaria, aunque ella misma dice: "Había decidido inmolar mi vida por Julio, Sofía, Cinthia" (Alarcón 77). Aun cuando en esta cita Julio es el primero en la lista de inmolación, su motivación deja entrever la coacción de la que es víctima. En el momento público de inculparse aparecen Sofía y Cinthia, hermana y sobrina respectivamente, como justificativas que tiene para ayudar a Julio. Hasta este punto, y aun con la agresión de Julio en su vida privada, ella continuaba su rol de sumisión consensual, pero en el momento de sacrificio público la sumisión de Fernanda revela su contexto y la opresión de la que es víctima.

Es evidente que el aspecto público del sacrificio muestra que la relación de Fernanda con Julio implica miedo, en la medida en que las familiares de Fernanda se encuentran en una posición vulnerable. Como indica Elsa Ivette Jiménez Valdez, en el narcotráfico el código de respetar a los familiares ya no existe (I2O). Fuera del ambiente doméstico, la relación entre Fernanda y Julio está supeditada a otros juegos de poderes de sumisión y dominación, dentro y fuera del mundo narco, lo que pone en evidencia que Julio no es un superior en todos los aspectos. Aunque Fernanda estaba castigada y separada de Julio, el juego de poderes del narcotráfico la continuaba rodeando. Ella, por tanto, está sometida a Julio, a enemigos de Julio y a estructuras gubernamentales, tales como la policía. El beso y el sacrificio enfatizan la vulnerabilidad de la posición de Fernanda e indican que la opresión que ella sufre va más allá de su relación consensual con Julio. 
A pesar de esta opresión, Fernanda consigue empoderarse porque su sacrificio hace que Julio repiense su relación con ella. Su sumisión pública propicia un cambio en la actitud de Julio, y dos aspectos en particular dejan en evidencia la transformación de Julio con respecto a Fernanda: el uso de un vocabulario afectivo representado por la palabra "princesa" y la propuesta de matrimonio, como se explica más adelante. A partir de la teoría de Friedrich Nietzsche sobre el señor y el esclavo, se explica la transformación de Julio y este ensayo propone que, cuando Julio pasa a ver cualidades y valores positivos en Fernanda, él deja de tratarla como un inferior absoluto y ella se empodera.

En el libro On the Genealogy of Morality (I887), específicamente el primer ensayo titulado "'Good and Evil,' 'Good and Bad"', Nietzsche expone la relación entre el señor y el esclavo.7 Aunque dicho ensayo no se relaciona directamente con los estudios sobre el BDSM consensual, el análisis que desarrolla ayuda a explicar la dinámica cambiante en la relación de sumisión y dominación consensual entre Fernanda y Julio. ${ }^{8}$ Nietzsche establece que una de las diferencias entre el señor y el esclavo es el concepto de moralidad, el cual está anclado en un determinado contexto y sujeto a varias características (15-16). La moralidad del señor está basada en valores dados a los hombres de clase socioeconómica alta, aristócratas y de determinado color de piel (13). Al mismo tiempo, esta moralidad les otorga valores opuestos a aquellos que pertenecen a grupos que considera inferiores, es decir, la clase pobre, los extranjeros, los que tienen otro color de piel, etc. (23). Si se considera que Nietzsche sostiene que el señor basa su moralidad en una definición propia de "nobleza" (20), el acto de sacrificarse le demuestra a Julio que Fernanda posee características positivas asociadas con su grupo social. El sacrificio hace que él reconozca que ella posee la moralidad del señor y no la del esclavo, la del inferior. Es decir, cuando los valores que él considera positivos aparecen en la "nena fresita", él ve lealtad y prueba de amor en el acto de inculparse. Él no se percata de la cohesión que Fernanda siente o de cómo ella protege a su hermana y sobrina.

Estas características nobles que Julio identifica son una referencia a los valores del mundo del narcotráfico, de modo que ella se empodera porque deja de ser una de muchas amantes, para ser su "reina". Por empoderamiento, me refiero a que Fernanda deja de ser una entre muchas buchonas para convertirse en la "reina" de Julio, posición que le permite actuar de la forma que quiere y tener todo lo que desea. Aun cuando se puede refutar que Fernanda se empodera, debido a que solo lo puede hacer porque Julio la autoriza, este ensayo propone que Fernanda sí se empodera. El que Fernanda mejore su posición significa que sus acciones constituyen 
empoderamiento, ya que por ser sumisa y buchona es asociada con una minoría típicamente marginada en el mundo del tráfico de drogas.

Respecto al empoderamiento de Fernanda, el primer cambio de Julio, que expone cómo el papel de ella se transforma, es usar un lenguaje amoroso que tenía prohibido, porque "A Julio también le había dicho que lo quería, pero sólo una vez, porque a él no le gustaba que uno anduviera hablando de más" (Alarcón 65). Él no deja que Fernanda hable de sus sentimientos, por lo que es evidente que Julio domina hasta en el lenguaje que Fernanda puede usar para expresarle su afecto. Después de que ella se sacrifica, Julio la rescata y le pregunta si en realidad se iba a inculpar para liberarlo a él, como si quisiera corroborar con palabras la determinación de ella (8o). Además, él le dice: "Perdóname, princesa" (83), por lo que se observa que se responsabiliza por los problemas que ella tuvo y la trata de forma diferente. Utilizar un vocabulario que expresa cariño hacia Fernanda es una novedad, porque hasta antes del sacrificio la había tratado como "fresita", "pinche nenita" (28), "pendeja" (30) y "vieja" (3I, 33).9

La nueva palabra implica un cambio en el estatus de Fernanda, ya que está conectada con el universo de metáforas del narcotráfico. Por ser novia de Julio, ella podía ser una "reina" pero Julio no la trataba de esta forma. En la categoría de "reinas" se encuentran las mujeres trofeo, así como las esposas, madres, hermanas, es decir, aquellas mujeres que conforman la familia de los hombres involucrados en el tráfico de drogas. "Reina" también se usa para referirse a la jefa que está a cargo del negocio (Santamaría 28; Valenzuela Arce 155) y a las buchonas. En este sentido, "princesa" indica el cambio de posición de Fernanda y su empoderamiento, ya que hasta ese entonces había sido sólo una estudiante universitaria como destaca Nora Guzmán (xxxiii), aunque con novio traficante. Después de "princesa" aparecen en la novela otras palabras relacionadas con Fernanda, tales como "majestad" (Alarcón II4), "reinita" (154, 203) y "reina" (2O2), las cuales se refieren a los cuentos de hadas y al sistema monárquico gubernamental. En México, estos términos también pertenecen al lenguaje afectivo, de modo que señalan que Fernanda se convierte en "reina" dentro del mundo del narcotráfico de Julio.

Cuando Julio utiliza la palabra "princesa", Fernanda le responde: "No me digas, 'princesa"' (Alarcón 83). Ella rechaza esa palabra porque, después de una pelea entre sus padres, su padre la buscaba, le daba regalos y la llamaba "princesa", con el propósito de reconciliarse con la madre de Fernanda (64). Debido a esta manipulación, Fernanda objeta dicho término para no repetir con Julio la dinámica de sentirse usada por su padre. Asimismo, debe considerarse que "princesa" disminuye su agencia y agenda, en la medida en que da a entender que Fernanda se inculpó por 
chantaje y no explica que ella tomó una decisión conscientemente. Rebelarse ante el uso de dicha palabra, entonces, significa que ella no es una de las "princesas" del rey, ya que se sacrificó a propósito, por lo que merece otra posición de más categoría, agenda y agencia que princesa: "reina".

La escritora Cristina Rivera Garza plantea que Fernanda desempeña varios roles en la novela: la esposa fiel, la buchona y la jefa ("reina del sur") (44).ı Puede verse que la posición de Fernanda cambia a lo largo de la novela, ya que de ser un inferior absoluto, que no posee una contraseña para detener al superior, Fernanda se sacrifica y luego pasa a empoderarse. Ella comienza a ser "reina" porque Julio admite su importancia, la trata mejor tanto en privado como en público e inclusive le propone matrimonio. Este pedido es su segundo cambio, ya que oficializa la relación entre ellos con toda la parafernalia del caso. Lo hace en una finca con "una mansión, caballerizas, caballos pura sangre, candelabros finos, una mesa dispuesta con flores y luz de velas y al fondo de la sala, a media luz, un trío de violinistas" (Alarcón ir8). El pedido en sí y el ambiente destacan que Fernanda deja de ser una de las muchas amantes para convertirse en la "reina", en la futura esposa. Sin embargo, como Fernanda señala, Julio no obtiene el consentimiento verbal de ella para casarse, sino que lo asume: "Y de hecho, él no esperó mi respuesta" (II8). Los celos y el sacrificio público cambian la posición de Fernanda, porque primero es una novia (buchona/amante) y luego princesa y prometida (reina), pero en un mundo donde él sigue siendo rey. Julio modifica el papel de Fernanda sin ceder su propia posición de poder, pero, como ya se explicó, esta situación no evita que Fernanda se empodere en el mundo del narcotráfico.

El cambio de Julio con respecto al papel de Fernanda tiene otras repercusiones, porque ella cambia cuando la dominación y sumisión consensuales que tenían se transforman. Al relacionar las ideas de Nietzsche con la sumisión de Fernanda, se propone que el culparse a sí misma para evitar que Julio sea apresado muestra que Fernanda, al sacrificarse, incorpora la mentalidad (moralidad) del señor. Es decir, que ella reproduce - voluntaria y coercitivamente - la jerarquía y cultura del contexto narcotraficante al que está sometida, en la medida en que salva al "señor" traficante.

Después del sacrificio, Fernanda se da cuenta que tiene una posición nueva porque Julio aclara que "un rasguño mío valía la vida de cualquiera" (Alarcón 87). El que hiera a Fernanda, así sea superficialmente, paga con su vida ya que el comandante que la hizo subir a la patrulla fue torturado y asesinado (86). La violenta reacción de Julio le confirma a Fernanda que ella pasa a ocupar la posición de "reina". Ahora puede obtener todo lo que quiera, pero su vida está en las manos de Julio (87). Al ser tratada de forma 
diferente y ser la prometida, Fernanda adquiere una posición nueva de poder que se observa cuando pasa dos semanas escondida en un hotel mientras se supone que está en Japón (132), o cuando le dice a Julio que hay que matar a su ex, Keila, y él le responde que puede hacer lo que quiera (I87). Si antes Fernanda no lo podía ni celar, después del cambio puede pedirle hasta acabar con sus ex, y la actitud permisiva de Julio sorprende a Fernanda: "Esa no era una respuesta. No de Julio. Antes era lo que él quisiera. Y punto" (187). Ella no está acostumbrada a que Julio le dé libertad de escoger y que la opinión de ella cuente. Por esto, el comportamiento de Julio se convierte en una paradoja que ella separa en antes y después, como cuando dice: "(Insisto: él no era Julio)" (I87).

Mónica E. Lugo Vélez señala que "Toda manifestación amorosa por parte de Julio la interpreta [Fernanda] como fragilidad en su carácter $y$, por consiguiente, esta nueva actitud de Julio estimula su otredad abominable" (44-45). Para Lugo Vélez, Fernanda se transforma en un monstruo indomable y autosuficiente porque el mundo del narcotráfico exacerba su mundo interior (26). A diferencia de esta idea, se plantea aquí que, al incorporar cuatro aspectos de la mentalidad del narcotráfico, Fernanda deja de estar localizada en la posición de inferior absoluto, ya que toma conciencia de que tiene otros beneficios y poder. Los cuatro aspectos son adquirir libertad sexual, dejar de ser sumisa como un perro, apropiarse de símbolos claves de la cultura del narcotráfico y exacerbar su materialismo.

El primer aspecto es importante en la medida en que ella comienza a ver que existen otros hombres, a pensar en ellos cuando tiene sexo con Julio y hasta tiene dos "aventuras," una con un colombiano-japonés y otra con un guardaespaldas. La dominación que tenía Julio se transforma, pero no se agota. La relación sexual con el colombiano-japonés representa infidelidad y, al mismo tiempo, trae a primer plano el placer sexual de Fernanda. Mientras tienen sexo, ella dice que, "De cuclillas, sobre él, por primera vez en mucho tiempo me preocupé por mi propio placer, por metérmelo y frotármelo a mi gusto, por seguir la velocidad que dictara mi deseo" (Alarcón 135). Fernanda procura su propio placer y no somete su deseo ante el placer del hombre con el que está, como con Julio. Al mismo tiempo, debido a que está encima (de cuclillas) en el acto sexual y determina el ritmo, ella está en una posición tradicionalmente vista como de poder y dominación.

Durante esta primera aventura, Fernanda también explica que: "Seguramente en ese momento mi perro estaría despierto. Yo me bebía la deliciosa noche y me comía un wey japonés de nacimiento, colombiano de ascendencia" (Alarcón I30). El que Fernanda experimente placer sexual con otro hombre mientras Julio la espera señala una inversión de roles que hace 
que ella se comporte como Julio lo hace con ella, por lo cual Fernanda adopta el papel del superior. Además, cuando se esconde las dos semanas en el hotel dice que, "Me sentía liberada: estaba en mi ciudad pero nadie lo sabía. Era como volver a ser yo. Como recomenzar" (I32). Durante este período, ella se apropia de su alma y cuerpo como si hubiera perdido el dominio de sí misma. Sin embargo, hay que destacar que no puede volver a ser la misma de antes porque sigue dependiendo de Julio económica y emocionalmente, aunque pasa a imitarlo al desarrollar su propia dominación con otros hombres en el ámbito sexual.

El segundo aspecto que muestra cómo Fernanda deja de ser un inferior absoluto es cuando abandona su papel de perro dócil, de completa sumisión. Así como la palabra "princesa", el término "perro" es recurrente en la novela y posee varias connotaciones. Fernanda es como un perro durante el sexo porque le gusta lamer a su pareja (Alarcón 13, I35), lo cual expone sus preferencias y necesidades de dar y recibir placer. ${ }^{\text {II }} \mathrm{Al}$ mismo tiempo, Fernanda asocia la palabra "perro" con su relación con Julio al reproducir constantemente la imagen de estar en los colmillos de él: "Cuando te vi quise albergarme en tus colmillos, que me apretara tu mandíbula, hacerme pequeña, tan pequeña. Mínima en tus mandíbulas, muñeca arruinada que escucha el crujir de sus propios huesos" (179). Esta imagen representa necesidades, peligro, sumisión y placer, y ratifica a Fernanda como participante inferior en una relación consensual del BDSM. Sin embargo, dicha imagen se modifica y pasa a mostrar el cambio de Julio: "Y ahora no me muerdes. Estas [sic] ahí, poniéndome tus ojos lastimeros. Esperando mis palabras. Tú no me muerdes" (I79). Habiendo sido antes peligroso y poderoso, Julio se debilita, mientras ella pasa a querer morder la carne asada de Keila (195). Habiendo sido perra que lame (literalmente), Fernanda se convierte en perra que quiere morder: "perra brava". Puede verse que su agencia y autonomía comienzan a destacarse cuando Julio la trata como "reina", debido a que tener esta posición en el mundo de Julio es más que acceder a un poder simbólico vacío. Tener una relación de parentesco oficial con un narcotraficante hace que Fernanda no sea solamente un trofeo, porque puede dar órdenes.

Además de dejar de ser sumisa como un perro, ser dueña de su sexualidad y buscar su propio placer, el tercer aspecto que contribuye a cambiar la posición de inferior absoluto de Fernanda son los narcocorridos del grupo "Cártel de Santa". Fernanda admite que no le gustaba esa música: "Cuando Julio empezó a hip hopear las rolas del Cártel de Santa yo lo soporté, pero cuando se afilió al Club de Fans Jauría de Perros, me alteré por andar con un wey so freak" (Alarcón 28). Ella rechaza este género musical y solamente se entusiasma con Babo, el cantante del grupo. Sin embargo, 
cuando asiste a la fiesta del Centro de Idiomas, mientras se esconde en el hotel, se entusiasma, baila y rima las letras de los narcocorridos que tanto despreciaba. Es inclusive consciente de que repite las letras misóginas que detestaba (I34). En esta fiesta, experimenta un tipo de exilio porque siente que oír las canciones es recuperar su español, su "trocito de casa" (I34). Al distanciarse del mundo de Julio donde estaba sumergida pero de cierta forma retraída en su casa, Fernanda se da cuenta de que estaba mucho más empapada de los valores culturales de este mundo. Mata-Navarro indica que temas pertinentes a la moda y la estética configuran identidades dentro del narcotráfico, por lo que ser parte de este mundo es tener que asumir sus referentes culturales (I46). Al sentirse sola y libre, Fernanda finalmente acepta como suyos los referentes de la cultura del superior - el narcotráfico - que los narcocorridos representan. En términos culturales, ella asume su rol de "reina" en dicho mundo.

El materialismo exacerbado es el cuarto aspecto que representa la modificación del rol de Fernanda y cómo ella se asume como "reina". Aunque ella ya era superflua, prefería la ropa de diseñador, darse grandes lujos y deseaba un carro mejor, por primera vez le fastidia que su hermana sea "pobre" y sus zapatos estén desgastados y pasados de moda (Alarcón II2). Dicha actitud demuestra que el discurso clasista de Fernanda se exacerba, lo que refleja la estratificación jerárquica del mundo del narcotráfico, en el cual ella pasó a ocupar una posición superior. Como "reina", pasa a juzgar hasta a su propia hermana, quien está fuera de dicho mundo y no puede llevar su nivel de vida. Fernanda pierde sus valores anteriores y pasa a perpetuar los de la cultural del superior.

Estos cuatro elementos del comportamiento de Fernanda, libertad sexual, pasar a ser perra que quiere morder, aceptar la cultura musical y medir todo a través de su estatus económico, la ubican en una situación en la que deja de ser inferior absoluto y marginal en el narcotráfico. Fernanda no es un monstruo, al contrario de lo que señala Lugo Vélez, sino que se apropia de la mentalidad del narcotráfico y la desarrolla a tal punto que se hace más visible que ella mide todo a través de estos valores. No se trata solamente de que Julio la vea como "señor" y ella deje de ser "esclava", para retomar los términos de Nietzsche, sino también de que ella se apropia y reproduce de la mentalidad del "señor". Puede verse que la novela no perpetúa estereotipos sobre las dinámicas de una relación de sumisión y dominación consensual, en la medida en que las categorías inferior y superior en la relación entre Fernanda y Julio fluctúan y están abiertas a renegociaciones.

A pesar de la libertad y nuevos valores que Fernanda adquiere, su relación con Julio no se deteriora. Ella no es la esclava oprimida que busca 
acabar con el señor, como sostiene Nietzsche. Fernanda tampoco pasa de sumisa a dominadora, como proponen Athena Alchazidu y Felipe Oliver, porque no hay inversión total de roles en la dinámica de dominación y sumisión de la pareja (Alchazidu 89; Oliver np). Aun cuando tiene su aventura con el extranjero y redescubre su placer, al comparar al colombiano-japonés con Julio en el plano sexual, Fernanda misma dice que: "Me di cuenta que prefería mil veces a mi perro" (Alarcón I35). Así, continúa poniendo a Julio en una posición de superioridad. El pronombre posesivo "mi" junto con el sustantivo "perro" señalan que ella se ve a sí misma y a Julio de forma diferente, porque cambia los sujetos y objetos de posesión. Esta mudanza significa que el juego de poder en el que Julio dominaba exclusivamente se ve infiltrado por el poder cada vez más fuerte de Fernanda.

Sin embargo, debe enfatizarse que aunque ella imita a Julio al tener amantes, no hace que Julio sea inferior con ella, porque le sigue dando prioridad: "Yo estoy con Julio y no voy a cambiarlo por nadie, mucho menos por ti" (Alarcón 150), como le dice al guardaespaldas con el que tiene la segunda aventura. Ella no busca reemplazar o someter a Julio, sino crear otras relaciones en las cuales ella es superior, ya que "no necesito que me den mi lugar porque yo puedo tomármelo" (I88). Fernanda no tenía antes esta conciencia, ya que ni siquiera poseía "su lugar" porque era una entre muchas buchonas, novias o amantes. La novela, por tanto, revela que estar en una relación de sumisión consensual no implica necesariamente ser inferior en todos los aspectos o con todas las personas.

Respecto al cambio de Fernanda, Sánchez Garay sugiere que el personaje no tiene cohesión porque deja de ser la universitaria superficial para volverse una "perra brava" (IO6). Por su parte, Luzelena Gutiérrez de Velasco indica que Fernanda se vuelve violenta porque sufrió violencia toda su vida (I09), y Amanda L. Matousek explica que hay una progresión en los niveles de violencia que Fernanda usa (I28). A diferencia de estas críticas, este ensayo propone que Fernanda ya era "perra brava", pero sólo puede demostrarlo cuando Julio se lo permite. Por ejemplo, sus celos aclaran que Julio continúa su dominación afectiva sobre ella, porque después de sacrificarse lo cela como nunca lo había hecho antes, ya que lo puede hacer, "No era la primera vez que me enteraba (o me enteraban) de esas cosas [otras amantes], pero esta vez sí tenía el valor de mandar todo a la verga" (Alarcón I86). En su posición de "reina", Fernanda puede actuar de la forma que hubiera querido antes, pero que Julio no le permitía.

Así, por ejemplo, antes de su sacrificio, Fernanda se va de una fiesta sin avisarle a Julio porque no quiere verlo con prostitutas, pero él la busca y le aclara: "A ver, cabrona, te me trepas a la camioneta porque no quieres que 
me baje por ti. Pues no, no quería que se bajara por mí, hacerle un drama en público podría costarme un hueso, tres huesos, la vida" (Alarcón I9I). Esta cita confirma que Fernanda no podía rebelarse ante Julio ni siquiera al verlo con otras mujeres. Es evidente que la Fernanda que era "perra brava" ya existía y podía morder, pero Julio no se lo permitía. Por tanto, puede verse que ella no se transforma en "perra brava", porque ya lo era, la diferencia es que sólo puede mostrarlo cuando Julio se lo permite y ella asume como propia la mentalidad del narcotráfico.

Al continuar empoderándose, sin embargo, Fernanda llega a cuestionar el poder de Julio, como cuando quema la casa donde vive Keila y muere el hijo de Julio con esa mujer (Alarcón 199). Ante este reto a su poder, él debe matarla o castigarla para no perder su posición de jefe y el respeto de sus hombres (203). Sin embargo, Julio prefiere no tocar a Fernanda y termina por suicidarse. En este ensayo se propone que el suicidio de Julio no señala la victoria del inferior, sino que expone que una relación consensual de sumisión y dominación puede liberar a la sumisa, en la medida en que le otorga la posibilidad de reconciliarse con sus traumas familiares.

En la escena final entre Julio y Fernanda, él le avisa que su castigo por haber matado al niño es que la violen todos los guardaespaldas, pero ella le responde diciendo que ya tuvo sexo con todos (Alarcón 203). Al despertarle celos y hacerlo sentirse traicionado en su "hombría", ella manipula la situación a su favor al mostrarle que no ha sido solamente su inferior. Sin embargo, debido a que Fernanda está mintiendo, sus intenciones demuestran su sumisión: "y le repetí, para que ya me ultimara, que ya me había metido con todos y cada uno de sus Cabrones" (204). Como señala Rivera Garza, Fernanda toma las riendas de los aspectos psicológicos del narcotráfico (44). De hecho, ella no busca tanto humillarlo como provocarlo, para que la mate y no toque ni a su hermana ni a su sobrina (202). Si en la primera lista de inmolación Fernanda ponía a Julio primero, en ésta su familia va de primeras.

Debe destacarse, no obstante, que de cierta manera Fernanda también incluye a Julio en la lista, debido a que ni se escapa, ni lo mata, ya que como "reina" lo puede hacer. Ella no domina sino que se somete a Julio al arriesgar su propia vida, pero es él quien queda dominado por el afecto que siente, "Si te mato es peor que matarme a mí mismo" (Alarcón 203). Julio determina su afecto y sexualidad por cuestiones públicas. Al reconocer su afecto por Fernanda y expresarlo públicamente, queda dominado por sus sentimientos y relación de parentesco. La novela propone entonces que tanto la sexualidad como las relaciones de pareja tienen un impacto en el mundo del narcotráfico, debido a que mujeres como Fernanda pueden ser utilizadas 
por otros para desestabilizar al capo y, a la vez, ellas mismas pueden manipular y minar el poder de un narcotraficante.

La novela de Alarcón, por tanto, enriquece el inventario de personajes femeninos de la narconovela mexicana, ya que no se trata de la típica mujer trofeo o buchona. Tampoco se trata de la gran jefa narcotraficante, personaje que aparece en novelas como Nombre de perro de Élmer Mendoza y Hielo negro de Bernardo Fernández Bef. A través de Fernanda, la novela muestra una diversidad de roles que las mujeres han pasado a tener en el narcotráfico, ya que la intervención de las mujeres mexicanas en el tráfico se ha incrementado en los últimos años (Santamaría 27, 44-45). Las mujeres han pasado a vender y contrabandear drogas, y pueden llegar a ser empresarias, jefas y hasta sicarias. ${ }^{12}$

Además de indicar nuevos roles, Perra brava también expone la complejidad del empoderamiento de Fernanda. La muerte de Julio no representa una victoria o liberación de la sumisión, porque para ella murió el "más hombre" (Alarcón 204). Debido a esto, la obra evita mostrar la sumisión como negativa y binaria, porque no promueve la idea de que el inferior pertenece a una categoría en la que alcanza el triunfo con la erradicación del superior. Lo único positivo para Fernanda con la muerte de Julio es vencer la hemofobia, ya que el cadáver le cae encima y ella bebe la sangre (204). Lugo Vélez señala acertadamente que el acto de beber la sangre de Julio es una muestra de amor y respeto por su dueño (52), aunque debe destacarse que también representa la reconciliación de Fernanda con sus traumas familiares. Ella no vomita ni se desmaya ante la sangre, sino que la bebe, la incorpora a su cuerpo, como si se tratara de un líquido que ya no le repulsa, que no le es abyecto. La sangre del superior le ayuda al inferior a superar su fobia, debido a que en la novela la sangre pasa de representar el asesinato de la madre a simbolizar el sacrificio liberador que Julio le proporciona a Fernanda. Por esto, de ser un líquido abyecto que le recuerda la experiencia traumática en su infancia, la sangre se convierte en un líquido purificador que reconcilia a Fernanda con su propia familia e historia. También, y gracias al poder del superior, Fernanda le pierde el miedo a su padre, ya que está retenido en el baúl del carro de Julio que Fernanda puede usar para escapar (202). Un guardaespaldas de Julio había encontrado al padre de Fernanda, quien estaba prófugo de la justicia. Puede verse que la relación de sumisión con Julio, en la que ella no tenía ni una contraseña, le permite a Fernanda empoderarse, imponerle límites al poder de Julio y superar sus traumas familiares.

La novela de Alarcón, por tanto, presenta una relación de sumisión y dominación consensual, en la que, cuando Fernanda se sacrifica públicamente, Julio cambia el papel de ella en la relación. En este sentido, 
Perra brava no desarrolla representaciones estereotipadas y negativas de dominación y sumisión en la que la/el inferior es únicamente abusada/o y no siente ningún placer, sino que muestra la complejidad de los afectos involucrados en una relación de pareja consensual que no es normativa y está inmersa en el mundo narcotraficante. Asimismo, las dinámicas de sumisión y dominación pueden modificarse y evolucionar con la influencia de ciertas variables o por decisión y consentimiento de los participantes, aun si su contexto es el del narcotráfico. No se trata de un mundo completamente sadomasoquista en el que no hay ninguna movilidad o beneficio, como en el descrito por Chancer.

El cambio de roles y poderes en la novela es diferente al que se presenta en otras obras mexicanas contemporáneas que se desarrollan en el mundo del narcotráfico y que incluyen personajes de mujeres en roles de sumisión voluntaria, como Miss Bala (2011).r3 En esta película, dirigida por Gerardo Naranjo, Laura (Stephanie Sigman) es forzada a participar en la operación del gran narcotraficante Lino (Noé Hernández). Sin embargo, cuando él le da la posibilidad de irse con la condición de no volver, al caminar de noche varias horas por la playa, Laura no se va. Aun cuando gracias a Lino, Laura realiza su deseo de haber sido elegida Miss Baja California y decide permanecer, el nivel de consentimiento de ella es cuestionable, ya que caminar por la playa a esa hora es peligroso y tener que dejar su casa es un cambio forzado y radical de vida. Al quedarse, Laura pasa a ser una participante casi consensual que es aún más oprimida por Lino y el mundo del narcotráfico. Primero, debe tener sexo con Lino y, segundo, es usada como chivo expiatorio entre Lino y los militares en el complot para fingir la muerte del capo. En este sentido, como participante inferior casi consensual, Laura no consigue empoderarse dentro del mundo que muestra la película de Naranjo.

La novela, en cambio, muestra que el mundo del narcotráfico no es solamente un negocio, sino también una sociedad compleja con movilidad social y empoderamiento, porque el poder y las jerarquías fluctúan. A partir de una relación consensual de sumisión y dominación, la obra cuestiona y destruye jerarquías en dicho mundo. Además de criar un personaje femenino complejo y reflejar los cambios de roles de las mujeres en el narcotráfico en México, como se señaló antes, el texto de Alarcón enriquece la narcoliteratura con su perspectiva sobre el BDSM consensual. Por un lado, la novela muestra que la amante o reina sumisa constituye más que un elemento de decoración para el traficante, puesto que ella puede empoderarse. Asimismo, el narcotraficante no representa necesariamente el mito de un único traficante con poder omnipotente. La posición de Julio puede ser socavada por jefas en el narcotráfico, como Mónica, por la policía, 
y hasta por personas dentro de su organización o familia, como su "reina". Por otro, la obra de Alarcón repiensa afectos y prácticas sexuales, porque a partir del placer y el dolor consensuales exhibe la complejidad de ciertos actos heterosexuales, y critica tanto la violencia intrafamiliar como la del narcotráfico. Específicamente, la novela desnaturaliza la visión machista de la heterosexualidad, en la cual la inferior o sumisa solamente es explotada y al superior nunca le preocupa el inferior. Perra brava propone que la participación consensual de una mujer sumisa en un mundo machista, tiene la capacidad de alterar roles y jerarquías en el narcotráfico. Aunque la estructura del poder permanece intacta, los roles de sus participantes, independientemente de su género y sexo, son susceptibles al cambio.

Dickinson College

NOTAS

I Se entiende el BDSM a partir de la definición de Staci Newmahr en Playing on the Edge (2OII), como "the collection of activities that involve the mutually consensual and conscious use, among two or more people, of pain, power, perceptions about power, or any combination thereof, for psychological, emotional, or sensory pleasure" (I8).

2 No se adopta la abreviatura " $\mathrm{D} / \mathrm{S}$ " para referirse a la dominación y sumisión porque la novela trata estas dinámicas como flexibles.

3 La palabra "fresita" se refiere a una persona de clase socioeconómica privilegiada que se comporta de manera superficial.

4 Al darse cuenta de la sangre, Fernanda grita y Julio la abofetea. Para limpiarse, ella se baña por horas en la tina, pero nunca le reclama a Julio: "No lloraría, no estropearía las cosas. Ese era mi único pensamiento claro” (Alarcón 23).

5 En una fiesta en la que Julio ignora a Fernanda, ella se siente agradecida y complacida por el interés que Mónica tiene en ella, y las dos terminan besándose.

6 Para más información, por favor referirse, entre otros, al libro Women Drug Traffickers: Mules, Bosses, and Organized Crime de Elaine Carey.

7 Para desarrollar su argumento, Nietzsche se basa en el cuarto capítulo de la Fenomenología del espíritu de Hegel.

8 Tener en cuenta las dinámicas de poder y opresión entre el señor y el esclavo de Nietzsche permite examinar las relaciones de poder entre los personajes en la novela. Debe aclararse que una de las críticas que más se le han hecho al BDSM consensual es que, al reproducir la dinámica entre esclavo y dueño, perpetúa el desbalance de poder y la desigualdad racial histórica. Sin embargo, 
estudiosos y practicantes del BDSM encuentran que la dinámica esclavo/señor de sumisión y dominación no perpetúa desigualdades, sino que las cuestiona al desnaturalizar y parodiar jerarquías y juegos de poderes (Weiss i95). Como señala Weiss, son las jerarquías y los juegos de poder los que crean subjetividades raciales (195).

9 En México, "pinche" significa despreciable, y "vieja” se usa, entre otras connotaciones, para referirse a la esposa o novia.

Io La reina del sur es una novela del español Arturo Pérez-Reverte en la cual la protagonista es una narcotraficante mexicana.

II El tema de ser perro también se relaciona con los narcocorridos del grupo "Cártel de Santa" que aparecen a lo largo de la novela. Estas canciones muestran múltiples connotaciones de la palabra perro, como en "Esa nena mueve el culo”, “Blah, blah, blah...”, "Mira quien vuelve al ıoo”, "Perros” y "Santa muerte". Tanto "perra" como "perro" significan ser fuerte, líder, fanático, guardaespaldas, sumiso y guardián.

I2 Las mujeres desempeñan funciones diversas y fluidas en el narcotráfico. MataNavarro explica que las "empresarias" administran el negocio narcotraficante, las "puchadoras" venden drogas a menor escala, las "dolareras" les intercambian dólares o pesos mexicanos a los narcotraficantes, las "burreras" llevan droga a menor escala y las "halconas" son espías en otros grupos (I6, 57, I35).

I3 La gran mayoría de las obras mexicanas que tratan el tema del narcotráfico no desarrollan personajes femeninos complejos en roles de sumisión consensual.

OBRAS CITADAS

aguilar sosa, yanet. "Perra brava', la historia de una mujer en el narco." Res. de Perra brava, de Orfa Alarcón. El Universal 28 abril 20ıо: S. pag. Web.

Alarcón, orfa. Perra brava. México: Planeta, 20 io.

ALCHAZIDU, ATHENA. "El imaginario de la violencia entre el miedo y la fascinación. Consideraciones en torno a Perra brava de Orfa Alarcón." Colindancias 6

(2OI5): 8I-IOO.

B E C M A N , A N R EA. The Social Construction of Sexuality and Perversion.

Deconstructing Sadomasochism. London: Palgrave, 2009.

CHANCER, LYN s. Sadomasochism in Everyday Life: The Dynamics of Power and

Powerlessness. New Brunswick: Rutgers UP, 1992.

F O UCAULT, M I CHEL. La voluntad del saber. México: Siglo XXI, 2005.

GUtiéRREZ DE VELASCO, LUZELENa. "La violenta transformación de la violencia en

Perra brava, de Orfa Alarcón." Romance Notes 54 (20I4): IO5-II. 
Gu ZM Án, N ORA. "La insurgenta de Carlos Pascual y Perra brava de Orfa Alarcón: dos señoritas mejicanas." Revista de literatura mexicana contemporánea 17.50 (20II): xxx-xxxvi.

JIMÉNEZ VALDEZ, ELSA IVETTE. "Mujeres, narco y violencia: resultados de una guerra fallida." Región y sociedad 4 (20I4): IOI-28.

LUGO VÉLEZ, MÓ NICA E. La narcoliteratura produce monstruos: estudio sobre la monstrificación en la figura de la mujer y el niño en las narconovelas Perra brava de Orfa Alarcón y Fiesta en la madriguera de Juan Pablo Villalobos. M.A. Tesis. U de Puerto Rico Recinto Mayagüez, 2013.

M A T A - NA V A R R O, I Z Z L Í N R. El cuerpo de la mujer vinculada al narcotráfico como narración de sus relaciones sociales. Tesis de Maestría. ITESO, 2013.

MA TO USE K, A MANDA L. "Shades of the Borderland Narconovela from Pastel to Sanguine. Orfa Alarcón's Perra brava as Anti-Novela." Frontiers 35.2 (2014): II842.

Miss Bala. Dir. Gerardo Naranjo. México. Canana Films, Fox International Productions, 2OII.

N EW M A H R, S T A I. Playing on the Edge: Sadomasochism, Risk, and Intimacy. Bloomington: Indiana UP, $201 \mathrm{I}$.

Niet ZSChe, fR IE DRich. On the Genealogy of Morality. Trad. Calor Diethe. Ed. Keith Ansell-Pearson. Cambridge: Cambridge UP, 2007.

oliver, felipe. "Ni perra ni brava” Res. de Perra Brava, de Orfa Alarcón. Crítica febrero 20II. S. pag. Web.

NÚÑEZ NORIEGA, GUILLERMO Y CLAUDIA ESTHELA ESPINOZA CID. "El narcotráfico como dispositivo de poder sexo-genérico: crimen organizado, masculinidad y teoría queer." Estudios de género de El Colegio de México 3.5 (2017): 90-I28.

PALAVERSich, DianA. "Narcoliteratura." Tierra adentro i67-68 (2010-20II): 55-63. Rivera Garza, Cris tina. "Perra brava" Res. de Perra Brava, de Orfa Alarcón. Milenio II mayo 20IO: 44. Web.

RUBIN, GAYLE. "Thinking Sex. Notes for a Radical Theory of the Politics of Sexuality." Deviations. A Gayle Rubin Reader. Durham: Duke UP, 20II: 137-8I. SÁNCHEZ GARAY, ElizABETh. "Ilusión mimética y punto de vista femenino en Perra brava de Orfa Alarcón." iMex 4.8 (2015): Ioo-ıo.

SANTAMARí A Gó MEZ, ARTURo. Introducción. Las jefas del narco. El ascenso de las mujeres en el crimen organizado. Coord. Arturo Santamaría Gómez. México: Grijalbo, 20I2. 27-52

valenzuela arce, josé manuel. Jefe de jefes. Corridos y narcocultura en México.

La Habana: Fondo Editorial Casa de las Américas, $200 \mathrm{I}$.

WE ISS, M AR G OT. Techniques of Pleasure. BDSM and the Circuits of Sexuality.

Durham: Duke UP, 2OII. 